\title{
Associative symmetry: II. Further studies of position learning in the gerbil
}

\author{
LEONARD BROSGOLE, ANN NEYLON, and PAUL ULATOWSKI \\ St. John's University, Jamaica, New York 11439
}

\begin{abstract}
In a series of studies, gerbils were trained to make a turn in a $\mathrm{Y}$ maze to escape from punishing heat. On every sixth trial there was an interpolated back run, with four groups being tested. The back run originated in the positive goal for two groups, with one group reinforced for returning to the startbox and the other group to the negative goal. The remaining groups ran back from the negative goal, one going to the start and the other to the positive goal. Symmetrical connections were found to occur during frontward training. As to the back runs, the animals having to return to the start demonstrated significantly better performance than the other groups, which in turn did not differ from each other. Thus, during forward learning the maze was cognitively structured, with the startbox established as the most highly preferred place of all. A second study indicated that the animals were attracted back to the start on the basis of a visual map, rather than by sebaceous odors deposited during forward training. The final study showed the appeal of the start to be so great that the animals departed from a cool goalbox, on the back runs, to return to a heated startbox.
\end{abstract}

In an earlier study, Brosgole and Lepak (1976) trained gerbils to position in a Y maze. While the floor of the startbox and alleys of the maze was heated to $45^{\circ} \mathrm{C}$, the floor of the negative goal was set at $50^{\circ} \mathrm{C}$, and the floor of the positive box was insulated so as to be at room temperature. Thus, escape from heat was used as an incentive for shaping a position response. The interior of the three boxes (i.e., start, positive, and negative goals) was clearly discriminable. One was black, the other white, and the third consisted of black and white vertical stripes. Doors were used to separate each of the boxes from the alley of the maze, which was painted a uniform gray. Thus, the color of the positive goal could not be seen from the choice point and the animals were presumably learning to make an appropriate turn only.

On every sixth run the animal was placed in the positive goal, which was then heated to $45^{\circ} \mathrm{C}$, and permitted to run back to either the start or negative goal, which were both insulated so as to be at room temperature. It was reasoned that perhaps the distinction between the three boxes enabled the maze to be cognitively structured during forward training through the development of symmetrical connections which, then, would have established the starting position as being far preferable to the negative goal. This being the case, the animals should have returned to the startbox, instead of committing the forward turn which would have led to the negative goal. The symmetry position was supported, as 86 of 96 animals preferred to return to the start.

\section{EXPERIMENT I}

This experiment was aimed at determining whether the obvious preference for the start in the prior study was based purely upon an avoidance of the negative goal, or if it would hold up even if the animal was allowed to run to the positive goal. Therefore, four groups were created. All received the same frontward training as before but differed from each other on the backward task. The back runs now consisted of learning trials, as correct responses were reinforced and errors punished just as in forward training. Groups 1 and 2 were reinforced for returning to the start, which was insulated so as to be at room temperature. While Group 1 began its back trial from the positive goal (set at $45^{\circ} \mathrm{C}$ ), Group 2 departed from the negative box (also at $45^{\circ} \mathrm{C}$ ). In order to return to the startbox, Group 1 had to perform a response that was opposite to its forward training, while Group 2 was able to fulfill the task by issuing the same response. The backward trial consisted of going from the positive to negative box for Group 3 and from negative to positive for Group 4. Therefore, Group 3 was able to transfer its forward response to the backward setting, while an opposite turn was demanded of Group 4. Refer to Table 1.

It was reasoned that, if the animals were merely acquiring a turn during forward training, then Groups 2 and 3 should have mastered their backward task significantly faster than Groups 1 and 4. However, if the animals were symmetrically structuring the maze around a highly preferred start location, then Groups 1

Table 1

Backward Task Requirements

\begin{tabular}{llll}
\hline & From & \multicolumn{1}{c}{ Ran } & $\begin{array}{c}\text { Response With } \\
\text { Respect to } \\
\text { Forward Turn }\end{array}$ \\
\hline Group 1 & Positive & Start & Opposite \\
Group 2 & Negative & Start & Same \\
Group 3 & Positive & Negative & Same \\
Group 4 & Negative & Positive & Opposite \\
\hline
\end{tabular}


and 2 should have reached criterion prior to Groups 3 and 4 . In addition, it appears that a comparison of Groups 1 and 4 would enable a statement to be made as to the preference of the startbox relative to the positive goal.

\section{Method}

Apparatus. A Y maze was constructed that was essentially the same as that previously used by Brosgole and Lepak (1976), except that the arms were reduced to 3 in. in width and the goalboxes were $4 \times 3$ in. and removable. This was done to minimize the amount of exploratory activity.

Procedure. Except for the creation of three new backward groups, the general procedure was identical to that of Brosgole and Lepak (1976). The inclusion of these three groups necessitated a rotation of the body of the maze relative to the floor prior to the back runs. While Group 1 was punished for going to the negative goal on the back run, Group 2 was punished for running to the positive box, and Groups 3 and 4 for entering the start. Thus, the $50^{\circ} \mathrm{C}$ plate had to coincide with the negative and positive boxes for Groups 1 and 2, respectively, and with the start for Groups 3 and 4. This meant that the maze had to be realigned on the floor for Groups 2-4, while no such adjustment was necessary for Group 1.

Subjects. Forty-eight female gerbils of the Mon/tum strain were used. They ranged in age from 5 to 8 weeks on the day of testing. They were assigned randomly to the four backward groups, with each treatment consisting of 12 animals.

\section{Results and Discussion}

Groups 1-4 mastered the forward task in a mean of $22.33,14.17,36.50$, and 25.75 front runs, respectively. These differences were not significant according to a one-way analysis of variance $(F=2.58$, df $=3 / 44)$. Therefore, the groups may be considered as matched on the forward task and legitimately compared on the basis of their backward performance.

On the back trials, Groups 1 and 2 began their criterion run to the start in 4.42 and 4.17 trials. While it took 13.4 trials for Group 3 to learn to go from the positive to negative goal, Group 4 required 21.0 trials to begin running consistently from negative to positive. The foul groups were found to differ significantly according to a one-way analysis of variance $(\mathrm{F}=14.86$, $\mathrm{df}=3 / 44, \mathrm{p}<.01$ ). While Groups 2 and 3 were able to transfer the forward response to the backward situation, Groups 1 and 4 were required to emit an opposite turn. Therefore, Groups 2 and 3 were compared to 1 and 4 in order to determine if the groups differed on the basis of the response demanded of them. No difference was found using the Scheffé multiplecomparisons test $(F=3.49)$, indicating that the relevance of the back to the forward turn was of no consequence.

While Groups 1 and 2 were allowed to return to the original starting position on the back trials, Groups 3 and 4 had to run to the negative and positive goals, respectively. Therefore, Groups 1 and 2 were compared to 3 and 4 in order to ascertain whether the groups differed in terms of place learning. This difference was significant according to the Scheffé $(\mathrm{F}=38.01, \mathrm{p}<.01)$, indicating that it was far easier to learn to return to the start than any other location. In addition, Groups 1 and 2 did not differ from each other $(F=.007)$. This showed that the animals were able to find their way back to the start with equal facility, regardless of the place in which the back run originated. Oddly enough, Groups 3 and 4 did not differ either $(F=6.55)$, demonstrating that location preferences in the maze were not contingent upon the receipt of positive or negative reinforcement.

A comparison of Groups 1 and 4 was of particular interest, because the two groups had to commit a response that was opposite to the forward turn. However, this opposing turn led Group 1 back to the start and Group 4 to the positive goal. The clearly superior performance of Group $1(\mathrm{~F}=31.33$, $\mathrm{p}<.01)$ showed that the start was highly preferred relative to the positive goal.

To summarize the above, forward training resulted in a symmetrical place learning of the maze. Just as in the prior study of Brosgole and Lepak (1976), the maze was cognitively structured with the startbox highly preferred. The preference for the start must have been based upon some factor other than reinforcement (primary and secondary), because during forward training it was heated sufficiently to initiate escape behavior. On the basis of reinforcement, then, the animals should have avoided the start on the back runs. Yet they learned to approach it with greater rapidity than when they went to the positive goal. The similarity in the performance of Groups 3 and 4 strongly pointed to the lack of any contingency between reward and location preference.

It may be contended that the start position was not preferred at all, but rather that the animals left an odorous trail running from the startbox to the positive goal on the forward trials. On the back runs, therefore, the animals in Groups 1 and 2 had only to follow their own scent to correctly return to the start position. Since Groups 3 and 4 did not have such an advantage, their performance was relatively poor. Such an argument was precluded by the methodological design of the experiment. It may be recalled that the body of the maze was rotated for Groups 2-4. This meant that every animal traversed the same section of the floor on the forward and backward trials. Accordingly, the groups should not have differed if chemical cues were used in selecting out the appropriate response. The fact that differences were obtained rules out olfaction as a viable argument.

\section{EXPERIMENT II}

Although the use of a chemical trail was effectively ruled out in the previous study, it is possible that the animals' behavior was steered by a sebaceous odor 
deposited upon the walls of the startbox. The utilization of such a cue was unlikely because sexually immature females were used throughout our studies. However, a methodological control was deemed necessary because territorial scent marking behavior, as improbable as it may have been, would have placed Groups 1 and 2 at a decided advantage. The logic of the following experiment simply was to permit the animals to mark the startbox on the forward run and to transfer the sebaceous odor from the start to the negative goal on each back run. This enabled us to determine if the animals' behavior was dominated by a visual map of the maze or the use of a chemical attractant.

\section{Method}

Subjects. Sixteen female Mongolian gerbils, strain Mon/tum, were used. They were 5-8 weeks of age on the date of testing.

Apparatus. The apparatus of the last experiment was again used. However, new removable goalboxes were constructed of heavy oak tag. They were fully reversible, i.e., capable of being turned inside out.

Procedure. Two groups of eight animals were tested. Both groups made their back runs from the positive goal to the start in accord with the procedure of the last experiment. Group 1 coincided exactly with the first group of the previous study except for the reduced N. Group 2 differed only on the back runs where the start and negative goalboxes were removed and interchanged, thereby effecting a transfer of any sebaceous residue from start to negative goal. The reverse side of the startbox was painted the color of the negative goal and vice versa. Thus, the color of the start and negative goal remained the same by turning the boxes inside out during the exchange.

\section{Results and Discussion}

Group 1 required a mean of 33.0 forward and 9.0 back runs to criterion, while Group 2 mastered the forward and backward tasks in 46.6 and 7.3 trials, respectively. According to a split plot factorial design, employing one within and one between factor, there was no main effect of groups $(F=1.7, \mathrm{df}=1 / 14)$, nor a Group by Task (forward and backward) interaction $(\mathrm{F}=2.8, \mathrm{df}=1 / 14)$. Again, backward performance was mastered in significantly fewer trials than forward learning $(F=48.4, \mathrm{df}=1 / 14, \mathrm{p}<.01)$. Therefore, the exchange of start and negative goals did not interfere with the performance of Group 2.

One further point is of interest. Upon completion of forward and backward criterion, the start and negative goals were interchanged for Group 1 in an attempt to determine if the sudden transfer of the sebaceous scent would disrupt backward performance. Six of the eight animals maintained their backward criterion without error for 2 additional days (12 consecutive correct responses), one animal made one error and returned to criterion, while the remaining animal made two errors and returned to criterion. Accordingly, it may be concluded that our findings are not based upon the utilization of olfactory cues created by sebaceous excretions.

\section{EXPERIMENT III}

Brosgole and Lepak (1976) noted that their animals hesitated greatly in leaving the startbox on the forward trials but made the return run with remarkable speed. This seemed to provide partial evidence indicating that the start position was preferred to the positive goal. This suspicion was strengthened in Experiment $I$, where it was shown that backward learning to a cool start occurred significantly faster than comparable learning to the positive box. This study was a logical extension of the prior ones in attempting to assess the attractiveness of the start. Inquiry was made as to whether or not a hot startbox would maintain its appeal by luring the animal out of a cool positive goal on the backward trials.

The study of Brosgole and Lepak (1976) was replicated, in that there was only one backward group which ran from the positive goal to the start. However, this experiment differed in that the back trial originated in a cool positive box, with the start and negative goal set at $45^{\circ} \mathrm{C}$. Therefore, the animals were required to run from a heated to a cool box in the forward trials and from a cool to a hot box on the return trip. The time spent in the startbox on the front runs and in the positive goal on the return was recorded. It would be expected that under such conditions the animals would spend as little time as possible in the startbox and exhibit a tremendous latency if at all leaving the positive goal; i.e., if the receipt of primary reinforcement was the most salient factor influencing the performance of the animal. However, if the startbox is as highly preferred as the earlier studies indicated, then the animals might be expected to leave the comfort of the positive goal with little hesitation to return to a punishing start.

\section{Method}

Subjects. Twelve female gerbils, strain Mon/tum, were used. They were from 6 to 14 weeks of age on the date of testing. Apparatus. The maze used by Brosgole and Lepak (1976) was employed.

Procedure. The procedure of Brosgole and Lepak (1976) was followed with the exception noted above. In addition, the animals were run until they either reached forward and backward criterion or completed 4 days of testing, whichever came first.

\section{Results and Discussion}

All animals met the forward criterion which was achieved in a median of 19.5 trials. Only eight animals reached the backward criterion, all returning to the start position. This was accomplished in a median of 3.5 trials, with half attaining backward prior to frontward criterion. Four gerbils failed to demonstrate the consistency necessary for operationally establishing a backward preference. However, in spite of an inability to achieve criterion, they continued to perform on the back trials. Therefore, all 12 animals contributed to the comparison of response latencies. 
The response latencies were found to be highly variable and too easily affected by the receipt of an extreme score in a single trial. The tremendous withingroup variability accompanied by a small sample size precluded a parametric analysis of response time. In spite of the instability of latency as an index of preference behavior, some meaningful statements can be made. On a per trial basis, a median of $12.35 \mathrm{sec}$ was spent in the start and $8.5 \mathrm{sec}$ in the positive goal. Nine of the 12 animals exhibited a greater latency in leaving the start than they did in departing from the positive goal. Although this difference was not significant according to the binomial test, a marked trend was quite apparent.

It was noted that, as the animals achieved forward criterion, there was an overall decrease in response latency, with the decrease most pronounced in the startbox. Prior to criterion, the median latency was $16.45 \mathrm{sec}$ in the start and $11.84 \mathrm{sec}$ in the goal. This difference was significant according to the sign test, as 10 of the 12 animals spent more time in the start $(p<.02)$. The median time in the start dropped to $9.68 \mathrm{sec}$ after criterion, compared to $6.84 \mathrm{sec}$ in the goal. This difference was not significant $(p=.073)$ even though nine animals still exhibited a preference for the start. It may be concluded that the stimuli in the start attracted a majority of animals in a magneticlike fashion to the extent that they endured punishment in return for being exposed to the startbox. Furthermore, the start seemed to be far more attractive than the positively reinforced stimuli of the goal.

These findings and conclusions are in full accord with our observations in the earlier studies. It must be remembered that in all of the prior experiments the animals were placed in a heated box on the back trials and ran for reinforcement. Whereas the forward trials took an obnoxiously long period of time, characterized by excessive exploratory behavior in the start, the return trip to the start was made with a ballistic-type motion. At times the back run occurred so rapidly that the experimenter was unaware that the trial had been completed.

Similar behavior often is seen when shaping an animal in a maze. They have to be encouraged or, at times, driven out of the start and lured into the positive goal. In addition, the literature indicates a direct relationship between running speed and proximity to the goal once the animal has finally achieved peak performance. Although this goal gradient has been explained in terms of reinforcement, it may very well be due to restraining forces exerted by the stimuli in the start.

Regardless of its etiology, the observed exploratory behavior had the net effect of exposing the animals disproportionately to those stimuli associated with the starting position in the maze. Thus, the stimuli in the startbox became relatively more familiar or available than those in any other location. According to Asch and Ebenholtz (1962), asymmetry is caused by differential item familiarity. In the case of verbal learning, the response terms become more familiar than the stimulus items and, hence, are more available for recall. Since the direction of recall is from the less to the more available item, forward surpasses backward performance. Our research indicates that the same obtains in instrumental learning, except that recall favored backward performance because of an enhanced familiarity with the start. Therefore, it may be concluded that bidirectional learning occurs in a maze with differential stimulus availability favoring backward recall.

One further point must be noted. By the nature of their design, the preceding studies may be reminiscent of the old "place vs. response" learning experiments and simply dismissed as such. The reader must keep in mind that the preference for and approach of "place" (the startbox) during the backward runs was not based upon perceptually available and discriminable stimuli. The notion of "place" existed solely within the organization of the animals' memory, and that organization could have been achieved only through the formation of bidirectional connections during forward learning. Accordingly, these studies have direct bearing upon the problem of associative symmetry.

\section{REFERENCES}

Asch, S. E., \& Eвenholtz, S. M. The principles of associative symmetry. Proceedings of the American Philosophical Society, 1962, 106, 135-163.

Brosgole, L., \& Lepax, C. Associative symmetry: I. Position learning in the gerbil. Bulletin of the Psychonomic Society, $1976,7,99-102$.

(Received for publication October 26, 1975.) 